\title{
3-Hydroxy-3-Methylglutaryl-CoA Reductase Inhibitors and Phosphodiesterase Type V Inhibitors Attenuate Right Ventricular Pressure and Remodeling in a Rat Model of Pulmonary Hypertension
}

\author{
Mitsutoshi Satoh, Akira Satoh \\ Department of Toxicology and Pharmacology, Faculty of Pharmaceutical Sciences, Toho University, Miyama 2-2-1, Funabashi, \\ Chiba, 274-8510, JAPAN
}

Received, October 12, 2008; Revised, December 20, 2008; Accepted, January 28, 2009; Published, January, 30,2009

ABSTRACT - Purpose. We examined the inhibitory
effects of 3-hydroxy-3-methylglutaryl (HMG)-CoA
reductase inhibitors, a prostacyclin analogue and a
phosphodiesterase type V inhibitor on hemodynamic
function and cardiac remodeling in rats with
monocrotaline-induced pulmonary hypertension. Methods. The rat model of pulmonary hypertension was created by administration of monocrotaline (70 $\mathrm{mg} / \mathrm{kg}$, s.c.) to male Wistar rats. A polyethylene tube was introduced into a left carotid artery for measurement of mean arterial pressure (MAP), another into the right ventricle via the right jugular vein for measurement of right ventricular systolic pressure (RVSP). Results. Repeated administration of atorvastatin $(2 \mathrm{mg} / \mathrm{kg} / \mathrm{day}$, p.o. 0 - 28 days $)$ and simvastatin ( $2 \mathrm{mg} / \mathrm{kg} /$ day, p.o. 0 - 28 days) significantly reduced RVSP and right ventricular weight $(\mathrm{RV}) / \mathrm{left}$ ventricular + septum weight $(\mathrm{LV}+\mathrm{S})$ without a change in MAP and heart rate. However, repeated administration of pravastatin $(4 \mathrm{mg} / \mathrm{kg} / \mathrm{day}$, p.o. $0-28$ days) did not reduce the monocrotaline-induced elevation of RVSP and RV/(LV $+\mathrm{S})$ significantly. The reduction of $\mathrm{RVSP}$ and $\mathrm{RV} /(\mathrm{LV}+\mathrm{S})$ induced by a combination of a prostacyclin analogue, beraprost (100 $\mu \mathrm{g} / \mathrm{kg} / \mathrm{day}, 0$ - 28 days) and simvastatin $(2 \mathrm{mg} / \mathrm{kg} /$ day, 0 - 28 days), was more potent than the effect induced by each drug alone. Sildenafil (5 mg/kg/day, 0 - 28 days) tended to reduce RVSP and $\mathrm{RV} /(\mathrm{LV}+\mathrm{S})$. Repeated combined administration of atorvastatin $(2 \mathrm{mg} / \mathrm{kg} / \mathrm{day}$, p.o. 0 - 28 days $)+$ sildenafil $(5 \mathrm{mg} / \mathrm{kg} /$ day, p.o. $0-28$ days) significantly reduced lung/body weight. Conclusion. Our present results suggest that repeated administration of the lipophilic HMG-CoA reductase inhibitors, atorvastatin and simvastatin, selectively attenuates the elevation of RVSP, development of pulmonary hypertension and right ventricular remodeling in rats with monocrotaline-induced pulmonary hypertension, and that a combination of
HMG-CoA reductase inhibitor and beraprost has a more potent effect than each agent alone. Although the significant inhibitory effect of sildenafil $(5 \mathrm{mg} / \mathrm{kg} /$ day $)$ alone were not observed, higher dosage of sildenafil might attenuate the elevation of RVSP, development of pulmonary hypertension and right ventricular remodeling in rats with monocrotaline-induced pulmonary hypertension.

\section{INTRODUCTION}

Pulmonary hypertension is a serious disease, characterized by progressive elevation of pulmonary arterial resistance, leading to right ventricular failure and death [1]. Although the causes of this disorder are complicated, abnormal vasoconstriction by vascular endothelial injury in pulmonary arterioles, smooth muscle cell proliferation and hypertrophy, contraction of arterioles and remodeling appear to be primary factors. It is reported that release of the vasodilators prostacyclin [2] and nitric oxide [3] decreases, on the other hand, the release of the vasoconstrictor thromboxane $\mathrm{A}_{2}$ [4] and the expression of endothelin-1 from vascular endothelial cells [5] increases. Therefore, a prostacyclin analogue, epoprostenol, has been administered by continuous intra-arterial infusion through catheters implanted into the superior vena cava in patients with pulmonary hypertension [6], and high doses of calcium-channel blockers have been administered to those who respond with reductions in pulmonary-artery pressure and pulmonary vascular resistance [7]. Recently, an oral prostacyclin analogue, beraprost [8], an orally administered dual

Corresponding Author: Dr Mitsutoshi Satoh, Department of Toxicology and Pharmacology, Faculty of Pharmaceutical Sciences, Toho University, 2-2-1 Miyama, Funabashi, Chiba, 274-8510, Japan. E-mail: satoh@phar.toho-u.ac.jp 
endothelin-receptor antagonist, bosentan [9], and the phosphodiesterase type $\mathrm{V}$ inhibitor, sildenafil [10], have been used in the treatment of pulmonary hypertension on the basis of the results obtained from randomized comparative clinical trials. These agents have a vasodilating effect in the pulmonary artery, and in addition, it has been suggested that the anti-cellproliferative effects of these agents, including 3hydroxy-3-methylglutaryl (HMG)-CoA reductase inhibitors, may be related to their clinical efficacy [1113].

Treatment with HMG-CoA reductase inhibitors (statins) reduces the incidence of myocardial infarction and death from cardiovascular causes and improves cardiovascular outcomes independently of their effects on cholesterol reduction $[14,15]$. Nishimura and coworkers [16] reported that simvastatin, an HMGCoA reductase inhibitor, attenuated vascular injury and remodeling in an animal model of pulmonary hypertension produced by monocrotaline and pneumonectomy. HMG-CoA reductase inhibitors have pleiotropic or cholesterol-independent effects and may be of benefit for the treatment of pulmonary hypertension as pulmonary vascular antiproliferative agents. These pleiotropic effects may be related to the ability of HMG-CoA reductase inhibitors to inhibit the synthesis of isoprenoid intermediates that are involved in intracellular signaling processes, thereby restoring endothelial function, inhibiting smooth muscle cell proliferation, and stimulating angiogenesis [17]. The immunosuppressive and anti-inflammatory properties of HMG-CoA reductase inhibitors contribute to the improved survival of patients with atherosclerosis $[15,18,19]$. HMG-CoA reductase inhibitors can suppress endothelial and vascular smooth muscle cell inflammatory and proliferative responses to injury [2022]). These effects involve inhibition of isoprenylation of rho- and rac-family GTPases that couple growth factor receptors to the intracellular MAP/ERK kinase signaling pathways and induction of the cell cycle inhibitor p27Kip1. [21]. HMG-CoA reductase inhibitors also improve endothelium-dependent relaxation through mechanisms that involve induction of endothelial nitric oxide synthase (eNOS) and nitric oxide production [23].

In this study, we evaluated differences among the hemodynamic properties of HMG-CoA reductase inhibitors and an oral prostacyclin analogue in rats with monocrotaline-induced pulmonary hypertension, and examined the preventive effects of HMG-CoA reductase inhibitors, a phosphodiesterase type $\mathrm{V}$ inhibitor, and a prostacyclin analogue on cardiac remodeling in this rat model.

\section{MATERIALS AND METHODS Materials}

Sildenafil citrate and atorvastatin calcium were supplied from Pfizer Inc. (Pfizer, USA). Monocrotaline and urethane were purchased from Wako Inc. (Wako, Tokyo, Japan). Monocrotaline was dissolved in $1 \mathrm{M}$ $\mathrm{HCl}$ at a concentration of $100 \mathrm{mg} / \mathrm{mL}$, then neutralized with $1 \mathrm{M} \mathrm{NaOH}$ and diluted with distilled water [24]. Beraprost sodium was purchased from Nichi-Iko Pharmaceutical Co., Ltd. (Toyama, Japan), pravastatin and simvastatin were from Merck-Hoei Co., Ltd., and heparin sodium was from Mochida Co., Ltd. All other chemicals used were commercially available and of analytical grade. Atorvastatin, simvastatin, pravastatin, beraptrost and sildenafil were suspended in $0.5 \% \mathrm{CMC}$ $\mathrm{Na}$ and administered orally $(5 \mathrm{~mL} / \mathrm{kg})$.

\section{Animals}

Three-week-old male Wistar ST rats were purchased from Sankyo Labo Service Co. (Tokyo, Japan), and given free access to water and commercial food pellets (MF: Oriental Yeast Co., Tokyo, Japan). They were kept in a temperature- $\left(24 \pm 1{ }^{\circ} \mathrm{C}\right)$ and humidity- $(55 \pm$ $5 \%$ ) controlled room with a 12 -h day-night cycle. All experiments were performed according to the guidelines of the Animal Research Committee of Toho University.

\section{Monocrotaline administration}

On Day 0, monocrotaline (70 $\mathrm{mg} / \mathrm{kg}$, s.c.) was administered to male Wistar rats weighing 81-110 g. The sham-treated rats $(N=7)$ received vehicle only.

\section{Treatment groups}

The monocrotaline-treated rats were divided at random, and given a single daily administration of either $0.5 \%$ CMC-Na solution as a vehicle-treated group, or atrovastatin, simvastatin, pravastatin, beraprost, sildenafil, simvastatin+beraprost and atrovastatin+sildenafil, orally. Eleven groups were studied: atorvastatin groups received atorvastatin (2 $\mathrm{mg} / \mathrm{kg}$, p.o. per day) form Day 0 to Day 28 (Atorva028, $N=10$ and Atorvastatin, $N=8$ ), simvastatin groups received simvastatin ( $2 \mathrm{mg} / \mathrm{kg}$, p.o. per day) form Day 
0 to Day 28 (Simva0-28, $N=10$ ) and from Day 14 to Day 28 (Simva14-28, N=9), pravastatin group received pravastatin (4 mg/kg, p.o. per day) form Day 0 to Day 28 (Prava0-28, $N=8$ ), beraprost group received beraprost $(100 \mu \mathrm{g} / \mathrm{kg}$, p.o. per day) form Day 0 to Day $28(N=8)$, sildenafil group received sildenafil $(5 \mathrm{mg} / \mathrm{kg}$, p.o. per day) form Day 0 to Day $28 \quad(N=8)$, simvastatin+beraprost group received simvastatin (2 $\mathrm{mg} / \mathrm{kg}$, p.o. per day $)+$ beraprost $(100 \mu \mathrm{g} / \mathrm{kg}$, p.o. per day) form Day 0 to Day $28 \quad(N=5)$, atrovastatin+sildenafil group received atorvastatin $(2$ $\mathrm{mg} / \mathrm{kg}$, p.o. per day) + sildenafil $(5 \mathrm{mg} / \mathrm{kg}$, p.o. per day) form Day 0 to Day $28 \quad(N=5)$ and vehicle group received $0.5 \%$ CMC-Na solution $(5 \mathrm{~mL} / \mathrm{kg}$, p.o. per day) form Day 0 to Day $28(N=10)$.

\section{Hemodynamic study in anesthetized rats.}

Twenty-eight days after monocrotaline $(70 \mathrm{mg} / \mathrm{kg}$, s.c.) or vehicle injection, all surviving rats were anesthetized with urethane $(1.0 \mathrm{~g} / \mathrm{kg}$, i.p.). After a tracheotomy, a polyethylene tube was inserted into the trachea to facilitate ventilation. Polyethylene tubes (PE50) were then inserted into the left carotid artery for measurement of mean arterial pressure (MAP), and the right ventricle via the right jugular vein for measurement of right ventricular systolic pressure (RVSP). The catheters inserted into the carotid artery or jugular vein were filled with heparinized saline. MAP and RVSP were measured by a pressure transducer (DX-360, Nihon Kohden, Tokyo, Japan). Heart rate (HR) was determined from the recorded arterial pulsation (AT-601G, Nihon Kohden, Tokyo, Japan). These parameters were recorded on a polygraph (WR3320, Nihon Kohden, Tokyo, Japan). After recovery from the cannulation procedure, baseline hemodynamics were measured.

\section{Organ weights}

At the end of the study, all the rats were sacrificed by injection of a high potassium solution under deep anesthesia, and the ventricles and lungs were excised, dissected free, and weighed. Atria were trimmed off, and the right ventricular free wall was carefully separated from the left ventricle plus septum $(L V+S)$. Then the right ventricular (RV) weight excluding the intraventricular septum was determined. The ratio of $\mathrm{RV}$ weight to $(\mathrm{LV}+\mathrm{S})$ weight $[\mathrm{RV} /(\mathrm{LV}+\mathrm{S})]$ and $\mathrm{RV}$ weight to body weight (RV/BW) were calculated as indices of right ventricular hypertrophy, and the ratio of lung weight to body weight (Lung/BW) was calculated as an index of pulmonary congestion. The degree of right ventricular remodeling was assessed as described previously [24].

\section{Statistical analysis}

Data are presented as means \pm S.E. The sham-treated and monocrotaline-vehicle groups were compared using Student's $t$ test. For multiple-group comparisons, ANOVA followed by Dunnett's multiple range test was performed. $\quad P<0.05$ was considered statistically significant. All data were analyzed by Stat View ver 5.0 (SAS Institute, Japan).

\section{RESULTS}

Inhibitory effects of HMG-CoA reductase inhibitors on monocrotaline-induced pulmonary hypertension As shown in Figures 1 and 2, RVSP, RV/(LV+S) and Lung/BW were increased in rats after 28 days of monocrotaline treatment. Repeated administration of atorvastatin (2 $\mathrm{mg} / \mathrm{kg} / \mathrm{day}, \quad$ p.o. 0 - 28 days $)$ significantly reduced RVSP, RV/(LV+S) and Lung/BW without any change in MAP and HR. Repeated administration of simvastatin $(2 \mathrm{mg} / \mathrm{kg} /$ day, p.o. $0-28$ days) also significantly reduced RVSP and $\mathrm{RV} /(\mathrm{LV}+\mathrm{S})$ without a change in MAP or HR. MAP and HR are shown in Table 1. Repeated administration of pravastatin $(4 \mathrm{mg} / \mathrm{kg} /$ day, p.o. 0 - 28 days $)$ did not significantly reduce the monocrotaline-induced elevation of RVSP, RV/(LV+S) and Lung/BW. Furthermore, repeated administration of simvastatin (2 $\mathrm{mg} / \mathrm{kg} /$ day, p.o. 14 - 28 days) did not reduce RVSP, $\mathrm{RV} /(\mathrm{LV}+\mathrm{S})$ or Lung/BW significantly. The inhibitory effects of atorvastatin, simvastatin and pravastatin on body weight, $\mathrm{RV}$, $\mathrm{LV}+\mathrm{S}$, lung weight, $\mathrm{RV} / \mathrm{BW}$, $(\mathrm{LV}+\mathrm{S}) / \mathrm{BW}$ and Lung/BW in rats with monocrotalineinduced pulmonary hypertension are summarized in Table 2.

Inhibitory effects of simvastatin and beraprost on monocrotaline-induced pulmonary hypertension

As shown in Figure 3, repeated administration of simvastatin $(2 \mathrm{mg} / \mathrm{kg} /$ day, p.o. 0 - 28 days $)$ significantly reduced RVSP and $\mathrm{RV} /(\mathrm{LV}+\mathrm{S})$ in monocrotalinetreated pulmonary hypertensive rats, and tended to reduce Lung/BW. Repeated administration of beraprost (100 $\mu \mathrm{g} / \mathrm{kg} /$ day, p.o. 0 - 28 days) significantly reduced RVSP and Lung/BW, and tended to reduce $\mathrm{RV} /(\mathrm{LV}+\mathrm{S})$. Repeated administration of simvastatin (2 
$\mathrm{mg} / \mathrm{kg} /$ day, p.o. 0 - 28 days $)+$ beraprost (100 $\mu \mathrm{g} / \mathrm{kg} /$ day, p.o. 0 - 28 days) significantly reduced RVSP, RV/(LV+S) and Lung/BW. The inhibitory effects of simvastatin and beraprost on body weight, $\mathrm{RV}$, LV+S, lung weight, $\mathrm{RV} / \mathrm{BW},(\mathrm{LV}+\mathrm{S}) / \mathrm{BW}$ and Lung/BW in rats with monocrotaline-induced pulmonary hypertension are summarized in Table 3 . As shown in Figure 3 and Table 3, combined repeated administration of simvastatin and beraprost prevented the elevation of RVSP, remodeling of the right ventricle, and the increase of the lung weight in this rat model.

Sham

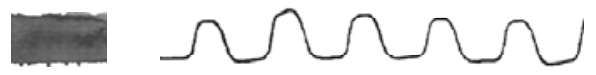

Vehicle
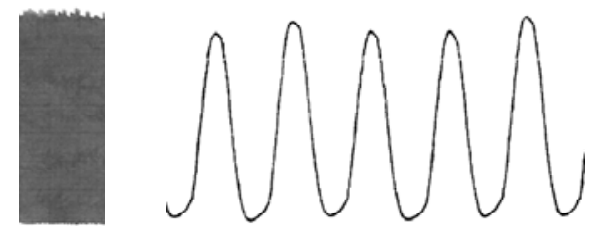

Atorva0-28
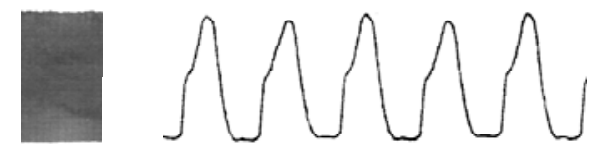

Simva0-28
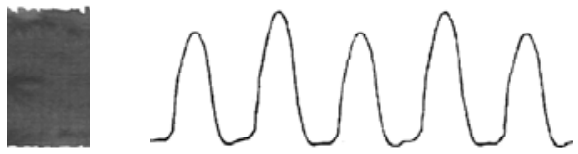

Simva14-28
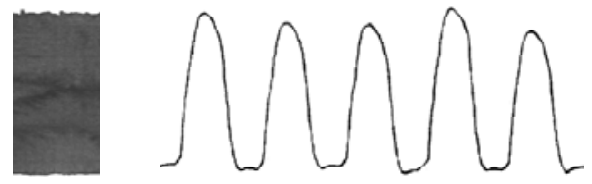

Prava0-28
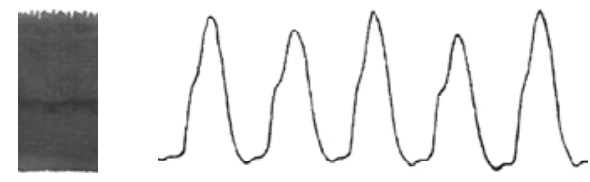

$100 \mathrm{mmHg}$

$30 \mathrm{~s}$

$0.5 \mathrm{~s}$

Figure 1. Typical tracings of right ventricular pressure in normal rats (Sham), monocrotaline-treated rats (Vehicle), and monocrotaline-treated rats subjected to repeated administration of atorvastatin (Atorva $\left.\mathrm{A}_{0-28}\right)$, simvastatin $\left(\mathrm{Simva}_{0-28}\right.$ and $\left.\mathrm{Simva}_{14-28}\right)$ and pravastatin $\left(\mathrm{Prava}_{0-28}\right)$. Sham: water was administered orally from the time of saline injection to $24 \mathrm{~h}$ before measurement of right ventricular pressure. Vehicle: right ventricular pressure was measured 28 days after monocrotaline treatment. 0-28: atorvastatin $(2 \mathrm{mg} / \mathrm{kg})$, simvastatin $(2 \mathrm{mg} / \mathrm{kg})$ and pravastatin $(4 \mathrm{mg} / \mathrm{kg})$ were administered orally from the time of monocrotaline injection to $24 \mathrm{~h}$ before measurement of right ventricular pressure. 14-28: simvastatin ( $2 \mathrm{mg} / \mathrm{kg})$ was administered orally from 14 days after the time of monocrotaline injection to $24 \mathrm{~h}$ before measurement of right ventricular pressure. 

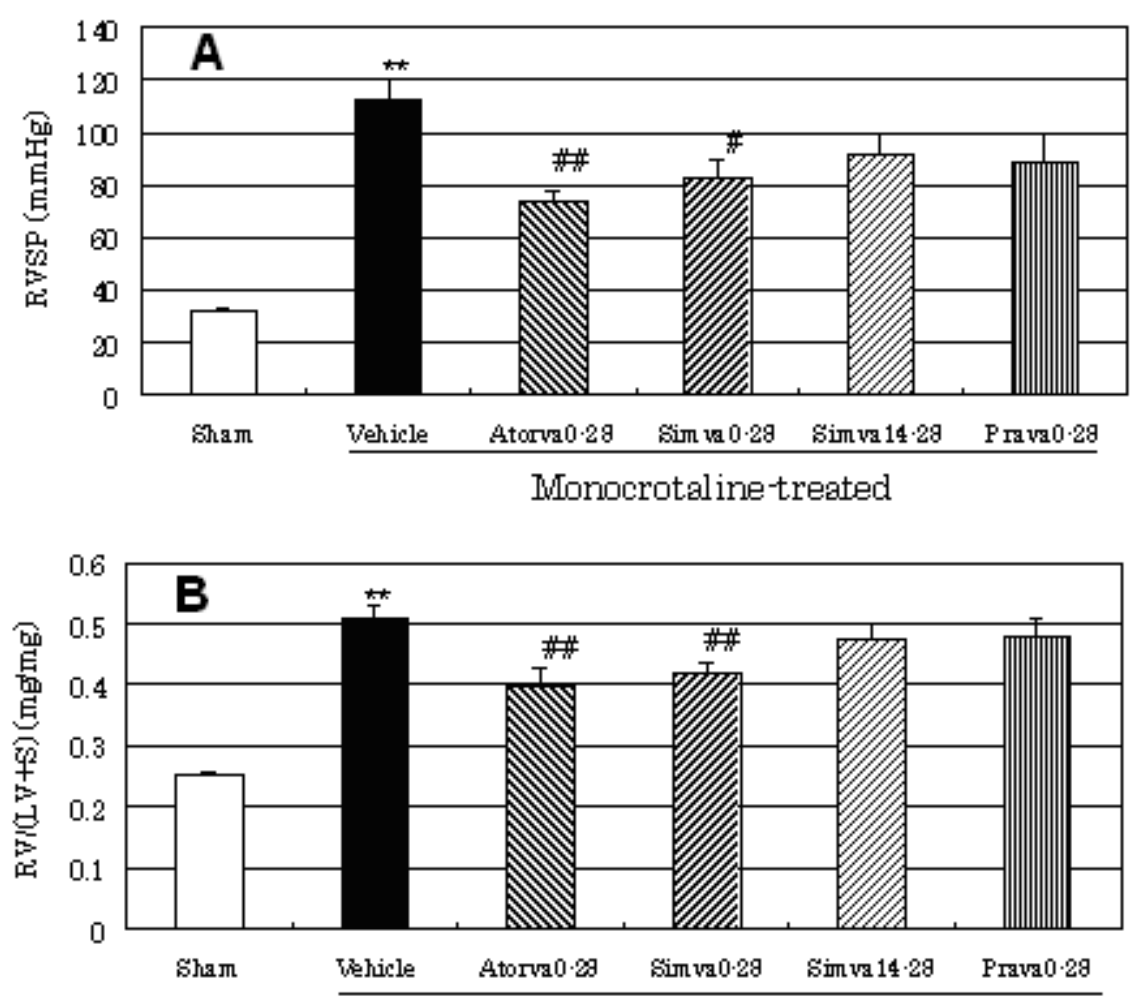

Monocrotal ine-treated

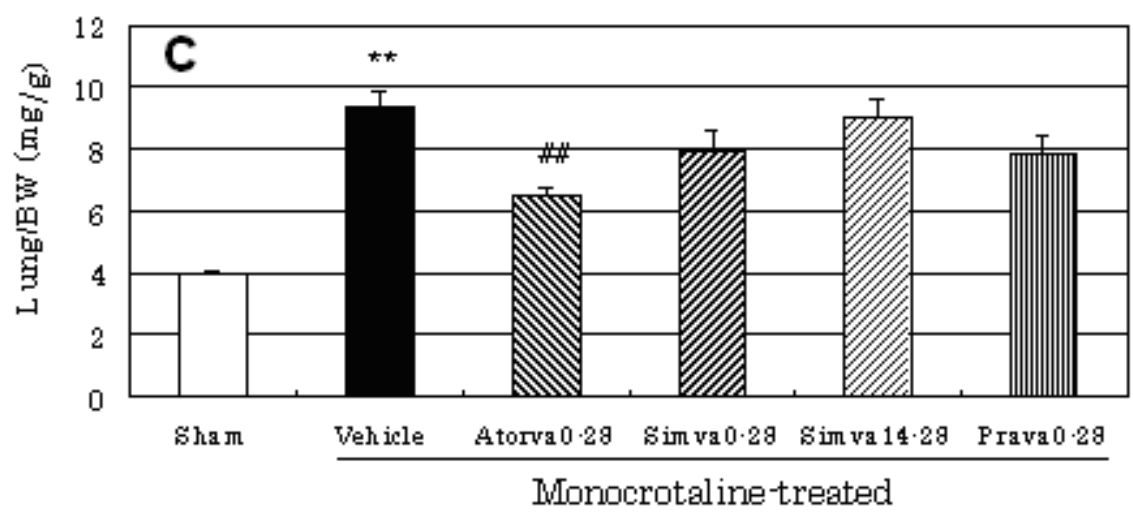

Figure 2. Inhibitory effects of repeatedly administered atorvastatin (Atorva), simvastatin (Simva) and pravastatin (Prava) on RVSP (A), RV/(LV+S) (B) and Lung/BW (C) in rats with monocrotaline-induced pulmonary hypertension. Sham: water was administered orally from the time of saline injection to $24 \mathrm{~h}$ before measurement of right ventricular pressure. Vehicle: water was administered orally from the time of monocrotaline injection to $24 \mathrm{~h}$ before measurement of right ventricular pressure. 0-28: atorvastatin $(2 \mathrm{mg} / \mathrm{kg})$, simvastatin $(2 \mathrm{mg} / \mathrm{kg})$ and pravastatin $(4 \mathrm{mg} / \mathrm{kg}) \mathrm{were}$ administered orally from the time of monocrotaline injection to $24 \mathrm{~h}$ before measurement of right ventricular pressure. 14-28: simvastatin $(2 \mathrm{mg} / \mathrm{kg})$ was administered orally from 14 days after the time of monocrotaline injection to $24 \mathrm{~h}$ before measurement of right ventricular pressure. The histograms indicate mean \pm S.E. $(n=7-10)$. $* * p<0.01$ vs. Sham $\# \mathrm{p}<0.05, \# \# \mathrm{p}<0.01$ vs. Vehicle 

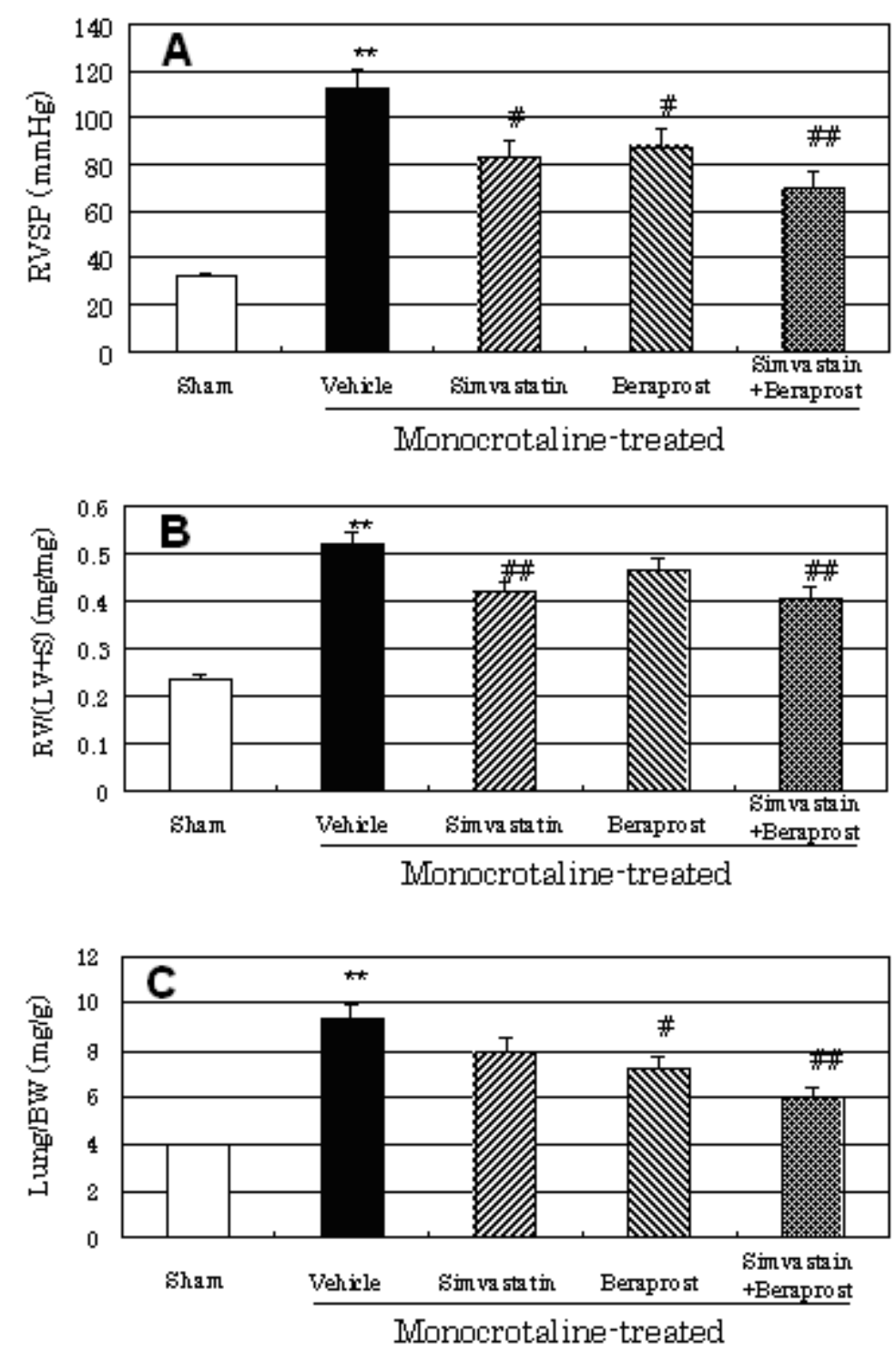

Figure 3. Inhibitory effects of repeatedly administered simvastatin, beraprost and simvastatin+beraprost on RVSP (A), RV/(LV+S) (B) and Lung/BW (C) in rats with monocrotaline-induced pulmonary hypertension. Sham: water was administered orally from the time of saline injection to $24 \mathrm{~h}$ before measurement of right ventricular pressure. Vehicle: water was administered orally from the time of monocrotaline injection to $24 \mathrm{~h}$ before measurement of right ventricular pressure. Simvastatin $(2 \mathrm{mg} / \mathrm{kg})$, beraprost $(100 \mu \mathrm{g} / \mathrm{kg})$ and simvastatin $(2 \mathrm{mg} / \mathrm{kg})+\mathrm{beraprost}(100 \mu \mathrm{g} / \mathrm{kg})$ were administered orally from the time of monocrotaline injection to $24 \mathrm{~h}$ before measurement of right ventricular pressure. The histograms indicate mean \pm S.E. $(n=5-10) .{ }^{*} p<0.01$ vs. Sham $\# p<0.05 \#$ \# $<0.01$ vs. Vehicle 
Table 1. Influence of atorvastatin (Atorva), simvastatin (Simva) and pravastatin (Prava) on mean arterial pressure (MAP) and heart rate (HR) in rats with monocrotaline-induced pulmonary hypertension.

\begin{tabular}{lcccccc}
\hline & Sham & Vehicle & Atorva $_{0-28}$ & Simva $_{0-28}$ & Simva $_{14-28}$ & Prava $_{0-28}$ \\
\hline MAP(mmHg) & $94.1 \pm 1.9$ & $96.7 \pm 2.1$ & $100.5 \pm 7.2$ & $98.0 \pm 4.5$ & $106.3 \pm 3.2$ & $103.0 \pm 4.3$ \\
HR(beats/min) & $362 \pm 14$ & $371 \pm 15$ & $355 \pm 22$ & $387 \pm 11$ & $377 \pm 8.0$ & $363 \pm 12$ \\
\hline
\end{tabular}

Sham: water was administered orally from the time of saline injection to $24 \mathrm{~h}$ before measurement of MAP and HR. Vehicle: MAP and HR were measured 28 days after monocrotaline treatment. 0-28: atorvastatin $(2 \mathrm{mg} / \mathrm{kg})$, simvastatin $(2 \mathrm{mg} / \mathrm{kg})$ and pravastatin $(4 \mathrm{mg} / \mathrm{kg})$ were administered orally from the time of monocrotaline injection to $24 \mathrm{~h}$ before measurement of MAP and HR. 14-28: simvastatin $(2 \mathrm{mg} / \mathrm{kg})$ was administered orally from 14 days after the time of monocrotaline injection to $24 \mathrm{~h}$ before measurement of MAP and HR. The data represent mean \pm S.E $(\mathrm{n}=7-10)$. There is no significant statistical difference

Table 2. Inhibitory effects of atorvastatin, simvastatin and pravastatin on tissue weight in rats with monocrotaline-induced pulmonary hypertension.

\begin{tabular}{lcccccc}
\hline & Sham & Vehicle & Atorva $_{0-28}$ & Simva $_{0-28}$ & Simva $_{14-28}$ & Prava $_{0-28}$ \\
\hline BW ( g ) & $246 \pm 5$ & $206 \pm 5^{* *}$ & $219 \pm 5$ & $203 \pm 4$ & $198 \pm 4$ & $191 \pm 3$ \\
RV ( mg ) & $142 \pm 5$ & $295 \pm 10^{* *}$ & $239 \pm 14^{\# \#}$ & $221 \pm 10^{\# \#}$ & $254 \pm 12$ & $250 \pm 11^{\#}$ \\
LV+S ( mg ) & $560 \pm 17$ & $562 \pm 17$ & $595 \pm 20$ & $533 \pm 14$ & $537 \pm 20$ & $547 \pm 17$ \\
Lung ( mg ) & $961 \pm 20$ & $1932 \pm 126^{* *}$ & $1416 \pm 69^{\#}$ & $1563 \pm 94^{\#}$ & $1717 \pm 106$ & $1551 \pm 154$ \\
RV/BW & $0.56 \pm 0.03$ & $1.45 \pm 0.05^{* *}$ & $1.10 \pm 0.07^{\# \#}$ & $1.08 \pm 0.05^{\# \#}$ & $1.33 \pm 0.07$ & $1.31 \pm 0.10$ \\
(LV+S)/BW & $2.23 \pm 0.05$ & $2.80 \pm 0.08^{* *}$ & $2.72 \pm 0.06$ & $2.65 \pm 0.05$ & $2.81 \pm 0.08$ & $2.75 \pm 0.14$ \\
Lung/BW & $3.86 \pm 0.10$ & $9.69 \pm 0.49^{* *}$ & $6.45 \pm 0.31^{\# \#}$ & $7.59 \pm 0.75$ & $9.01 \pm 0.62$ & $9.36 \pm 1.33$ \\
\hline
\end{tabular}

BW: body weight, RV: right ventricular weight, $\mathrm{LV}+\mathrm{S}$ : weight of left ventricle plus septum, RV/BW: ratio of RV weight to body weight, $(\mathrm{LV}+\mathrm{S}) / \mathrm{BW}$ : ratio of $\mathrm{LV}+\mathrm{S}$ weight to body weight, $\mathrm{Lung} / \mathrm{BW}$ : ratio of lung weight to body weight. Sham: water was administered orally from the time of saline injection to $24 \mathrm{~h}$ before sacrifice. Vehicle: water was administered orally from the time of monocrotaline injection to $24 \mathrm{~h}$ before sacrifice. 0 -28: atorvastatin (2 $\mathrm{mg} / \mathrm{kg})$, simvastatin $(2 \mathrm{mg} / \mathrm{kg})$ and pravastatin $(4 \mathrm{mg} / \mathrm{kg})$ were administered orally from the time of monocrotaline injection to $24 \mathrm{~h}$ before sacrifice. 14-28: simvastatin $(2 \mathrm{mg} / \mathrm{kg})$ was administered orally from 14 days after the time of monocrotaline injection to $24 \mathrm{~h}$ before sacrifice. The data represent mean \pm S.E $(n=7-10)$.

** $\mathrm{p}<0.01$ vs. Sham $\# \mathrm{p}<0.05 \#$ \# $<0.01$ vs. Vehicle. 
Table 3. Inhibitory effects of simvastatin and beraprost on tissue weight in rats with monocrotaline-induced pulmonary hypertension.

\begin{tabular}{lccccc}
\hline & Sham & Vehicle & Simvastatin & Beraprost & $\begin{array}{c}\text { Simvastatin } \\
\text { + Beraprost }\end{array}$ \\
\hline BW ( g ) & $247 \pm 6$ & $207 \pm 4^{* *}$ & $198 \pm 6$ & $203 \pm 4$ & $202 \pm 8$ \\
RV ( mg ) & $140 \pm 5$ & $291 \pm 10^{* *}$ & $219 \pm 10^{\#}$ & $260 \pm 16$ & $213 \pm 11^{\#} \ddagger$ \\
LV+S ( mg ) & $549 \pm 19$ & $575 \pm 19$ & $535 \pm 16$ & $562 \pm 16$ & $534 \pm 24$ \\
Lung ( mg ) & $970 \pm 19$ & $1933 \pm 109^{* *}$ & $1564 \pm 116^{\#}$ & $1456 \pm 91^{\#}$ & $1197 \pm 63^{\#} \dagger$ \\
RV/BW & $0.57 \pm 0.02$ & $1.41 \pm 0.06^{* *}$ & $1.11 \pm 0.04$ & $1.29 \pm 0.09$ & $1.07 \pm 0.09$ \\
$(\mathrm{LV}+\mathrm{S}) / \mathrm{BW}$ & $2.23 \pm 0.07$ & $2.78 \pm 0.08^{* *}$ & $2.68 \pm 0.07$ & $2.77 \pm 0.09$ & $2.67 \pm 0.14$ \\
Lung/BW & $3.94 \pm 0.11$ & $9.37 \pm 0.53^{* *}$ & $8.03 \pm 0.58$ & $7.21 \pm 0.50^{\#}$ & $6.02 \pm 0.43^{\#}$ \\
\hline
\end{tabular}

BW: body weight, RV: right ventricular weight, $\mathrm{LV}+\mathrm{S}$ : weight of left ventricle plus septum, RV/BW: ratio of RV weight to body weight, $(\mathrm{LV}+\mathrm{S}) / \mathrm{BW}$ : ratio of $\mathrm{LV}+\mathrm{S}$ weight to body weight, $\mathrm{Lung} / \mathrm{BW}$ : ratio of lung weight to body weight. Sham: water was administered orally from the time of saline injection to $24 \mathrm{~h}$ before sacrifice. Vehicle: water was administered orally from the time of monocrotaline injection to $24 \mathrm{~h}$ before sacrifice. Simvastatin $(2 \mathrm{mg} / \mathrm{kg})$, beraprost $(100 \mu \mathrm{g} / \mathrm{kg})$ and simvastatin $(2 \mathrm{mg} / \mathrm{kg})+$ beraprost $(100 \mu \mathrm{g} / \mathrm{kg}) \mathrm{were}$ administered orally from the time of monocrotaline injection to $24 \mathrm{~h}$ before measurement of right ventricular pressure. The data represent mean \pm S.E. $(n=5-10)$. ${ }^{* *} \mathrm{p}<0.01$ vs. Sham $\# \mathrm{p}<0.05$ vs. Vehicle $\dagger \mathrm{p}<0.05$ vs.

Simvastatin $\ddagger \mathrm{p}<0.05$ vs. Beraprost

\section{Inhibitory effects of atorvastatin and sildenafil on monocrotaline-induced pulmonary hypertension}

Repeated administration of atorvastatin $(2 \mathrm{mg} / \mathrm{kg} /$ day, p.o. 0 - 28 days) significantly reduced RVSP, $\mathrm{RV} /(\mathrm{LV}+\mathrm{S})$ and Lung/BW in monocrotaline-treated pulmonary hypertensive rats (Figure 4). The phosphodiesterase type $\mathrm{V}$ inhibitor, sildenafil (5 $\mathrm{mg} / \mathrm{kg} /$ day, p.o. 0 - 28 days) tended to reduce RVSP, but not to a significant degree. A combination of atorvastatin $(2 \mathrm{mg} / \mathrm{kg} /$ day, p.o. 0 - 28 days $)+$ sildenafil (5 mg/kg/day, p.o. 0 - 28 days) reduced Lung/BW significantly.

\section{DISCUSSION}

Our studies of rats with monocrotaline-induced pulmonary hypertension confirmed that repeated administration of atorvastatin and simvastatin reduced the monocrotaline-induced elevation of RVSP and hypertrophy of the right ventricle, and that combination treatment with simvastatin and beraprost was more effective against pulmonary hypertension. A subcutaneous injection of monocrotaline induces damage to endothelial cells, followed by new muscularization of the pulmonary vasculature and concomitant elevation of pulmonary arterial pressure, therefore resulting in right ventricular hypertrophy [24, 25]. Endothelial damage is apparent at an early stage, and the development of pulmonary hypertension is observed 14 days after monocrotaline injection [26]. Several proteases and inflammatory cytokines, vasoconstrictors such as endothelins or thromboxane $\mathrm{A}_{2}$, and vasodilators such as prostacyclin or nitric oxide play various roles in these processes. In the present study, we also observed elevation of RVSP, development of RV remodeling, and an increase in lung weight 28 days after monocrotaline injection (Figure 2 and Table 2). These changes were typical of the manifestations of pulmonary hypertension reported previously [27].

It was observed that the elevation of RVSP, development of RV remodeling, and an increase in lung weight were inhibited by repeated oral administration of atorvastatin $(2 \mathrm{mg} / \mathrm{kg})$ and simvastatin $(2 \mathrm{mg} / \mathrm{kg})$ from the time of monocrotaline injection for up to 28 days. These inhibitory effects of atorvastatin and simvastatin are due to the pleiotropic effects of HMGCoA reductase inhibitors. Kwak et al. (2000) [18] 


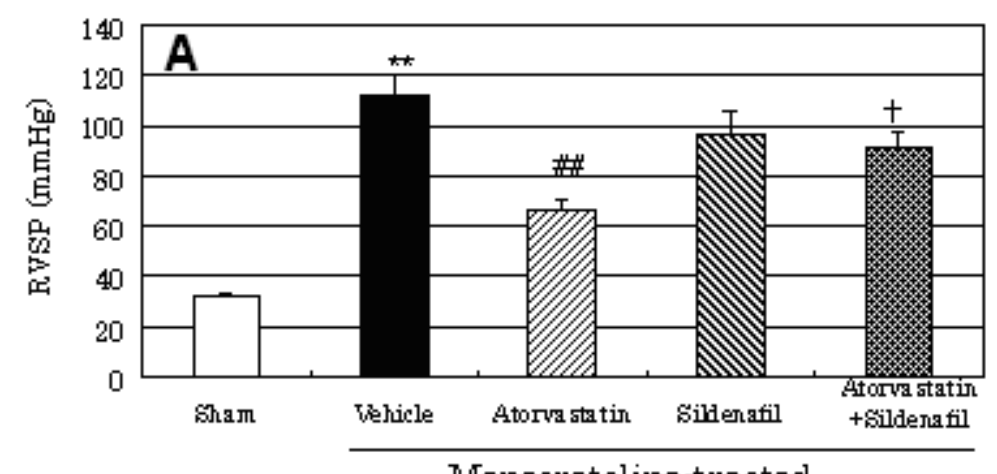

Monocrotaline-treated
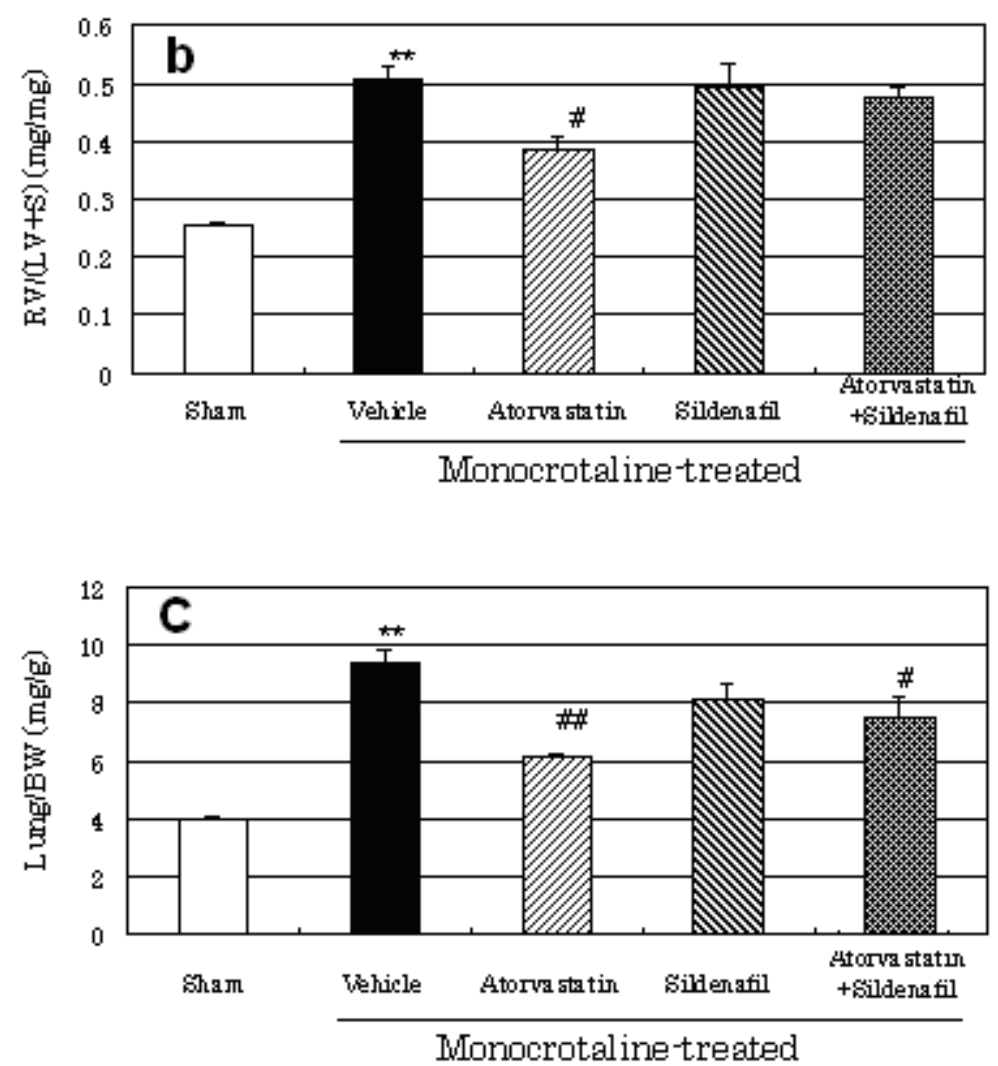

Figure 4. Inhibitory effects of repeatedly administered atorvastatin, sildenafil and atorvastatin + sildenafil on RVSP (A), $\mathrm{RV} /(\mathrm{LV}+\mathrm{S})(\mathrm{B})$ and Lung/BW (C) in rats with monocrotaline-induced pulmonary hypertension. Sham: water was administered orally from the time of saline injection to $24 \mathrm{~h}$ before measurement of right ventricular pressure. Vehicle: water was administered orally from the time of monocrotaline injection to $24 \mathrm{~h}$ before measurement of right ventricular pressure. Atorvastatin $(2 \mathrm{mg} / \mathrm{kg})$, sildenafil $(5 \mathrm{mg} / \mathrm{kg})$ and atorvastatin $(2 \mathrm{mg} / \mathrm{kg})+$ sildenafil $(5$ $\mathrm{mg} / \mathrm{kg}$ ) were administered orally from the time of monocrotaline injection to $24 \mathrm{~h}$ before measurement of right ventricular pressure. The histograms indicate mean \pm S.E. $(n=6-10) . * * p<0.01$ vs. Sham $\# p<0.05$ vs. Vehicle $\# \# p<0.01$ vs. Vehicle $† p<0.05$ vs. Atorvastatin 
reported that HMG-CoA reductase inhibitors act as direct inhibitors of the induction of major histocompatibility complex class II (MHC-II) by interferon- $\gamma$ and as repressors of MHC-II-mediated Tcell activation, and that these effects are due to inhibition of the inducible promoter of the transactivator gene, being evident in several cell types, including primary human endothelial cells and monocyte-macrophages. Laufs et al. [28] reported that HMG-CoA reductase inhibitors up-regulate endothelial nitric oxide synthase expression by blocking rho geranylgeranylation. Also, Indolfi et al. [22] reported that simvastatin inhibits vascular smooth muscle cell proliferation in vitro and neointima formation in vivo after vascular injury. These results suggest that the inhibitory effect of HMG-CoA reductase inhibitors on inflammatory cell infiltration into the perivascular space may prevent vascular endothelial injury in pulmonary arterioles and primary factors involved in the development of monocrotaline-induced pulmonary hypertension. It is indicated that HMG-CoA reductase inhibitors have anti-inflammatory effects, and can inhibit vascular smooth muscle cell proliferation and increase nitric oxide by up-regulating the expression of endothelial nitric oxide synthase. These effects prevent remodeling and vasoconstriction of the pulmonary vasculature, thus preventing elevation of right ventricular pressure. In addition, HMG-CoA reductase inhibitors prevent the development of aortic-banded or angiotensin II-induced left ventricular hypertrophy mediated through blockade of ras or rho isoprenylation $[29,30]$, suggesting that HMG-CoA reductase inhibitors directly inhibit hypertrophy in pulmonary hypertension.

In the present study, repeated oral administration of simvastatin from 14 days after monocrotaline injection up to 28 days did not reduce RVSP, $\mathrm{RV} /(\mathrm{LV}+\mathrm{S})$ and Lung/BW, significantly. After monocrotaline-induced endothelial damage and muscularization of the pulmonary vasculature had progressed, the pulmonary hypertension-preventing effects of HMG-CoA reductase inhibitors was weaker than those of HMG-CoA reductase inhibitors administered from the time of monocrotaline injection for up to 28 days. Repeated oral administration of pravastatin from the time of monocrotaline injection for up to 28 days did not significantly reduce the elevation of RVSP, RV/(LV+S) and Lung/BW (Figure 2 and Table 2). And although the survival ratio was improved by the repeated oral administration of simvastatin to the monocrotaline-treated rats, the improvement of survival ratio was not observed in the repeated oral administration group of pravastatin (data not shown). These results suggest that the inhibitory effects of pravastatin on the elevation of RVSP, development of pulmonary hypertension and right ventricular remodeling in rats with monocrotalineinduced pulmonary hypertension is weaker than those of simvastatin. Schachter [31] reported that the amount of transfer of hydrophilic HMG-CoA reductase inhibitors such as pravastatin to the intracellular compartment is smaller than for lipophilic HMG-CoA reductase inhibitors. It is reported that the treatment with simvastatin improved survival ratio of the patients with coronary heart disease [32], however, pravastatin did not reduce either mortality or coronary heart disease [33]. So the pleiotropic effects of pravastatin on cardiac muscle cells may be weaker than those of atorvastatin and simvastatin.

Repeated administration of beraprost from the time of monocrotaline injection for up to 28 days significantly reduced RVSP, but did not significantly reduce $\mathrm{RV} /(\mathrm{LV}+\mathrm{S})$, an index of right ventricular hypertrophy (Figure 3A and B). Repeated administration of simvastatin + beraprost from the time of monocrotaline injection for up to 28 days significantly reduced RVSP, RV/(LV+S) and Lung/BW. As the release of prostacyclin is decreased in monocrotaline-induced pulmonary hypertensive rats [2], oral administration of the prostacyclin analogue beraprost is an effective treatment for pulmonary hypertension. Beraprost potently inhibits platelet aggregation, the production of inflammatory cytokines, and proliferation of the human pulmonary artery via a cAMP-dependent pathway [34]. Beraprost inhibited the increase of RVSP, but did not inhibit right ventricular hypertrophy, reflecting the fact that HMG$\mathrm{CoA}$ reductase inhibitors such as atorvastatin and simvastatin inhibit ventricular hypertrophy directly, whereas beraprost does so indirectly through the prevention of pressure overload. In the present study, combination therapy with simvastatin and beraprost was more effective than monotherapy with either agent alone. It is suggested that HMG-CoA reductase inhibitors and beraprost exert their cardiovascular protective properties through different mechanisms. Namely, HMG-CoA reductase inhibitors inhibit the development of hypertrophy via a pleiotropic effect by 
blocking ras or rho isoprenylation, whereas beraprost inhibits the production of inflammatory cytokines and proliferation of ventricular cells via a cAMP-dependent pathway [17, 35]. As shown in Figure 4, the phosphodiesterase type $\mathrm{V}$ inhibitor sildenafil (5 $\mathrm{mg} / \mathrm{kg} /$ day) did not show any significant inhibitory effects on RVSP, RV/(LV+S) and Lung/BW in monocrotaline-induced pulmonary hypertensive rats. Monotherapy with sildenafil ( 25 or $75 \mathrm{mg} / \mathrm{kg} /$ day) attenuates the elevation of pulmonary artery pressure and vascular remodeling in hypoxia-induced pulmonary hypertension [36], whereas combination therapy with sildenafil (25 $\mathrm{mg} / \mathrm{kg} /$ day $)$ and beraprost (100 $\mu \mathrm{g} / \mathrm{kg} /$ day) attenuates the development of monocrotaline-induced pulmonary hypertension [37]. Sildenafil (100 mg/kg/day) was efficacious in rats with pulmonary hypertension, and the combination therapy of sildenafil and bosentan showed an additional effect for decreasing pulmonary arterial pressure, maintaining body weight, and reducing mortality [38]. Andersen et al. (2005) [39] reported that sildenafil $(10 \mathrm{mg} / \mathrm{kg} / \mathrm{day})$ attenuated the elevation of RVSP and right ventricular hypertrophy but did not inhibit vascular remodeling in hypoxia-induced pulmonary hypertension. In some clinical studies it is reported that the clinical efficacy of treatment with sildenafil monotherapy or combination therapy in patients with pulmonary hypertension [40, 41]. We need to perform additional studies treated with higher dose of sildenafil in monocrotaline-induced pulmonary hypertensive rats, including new phosphodiesterase type V inhibitors, tadalafil [42] and valdenafil [43]. Further experiments using additional doses of sildenafil and comparison of properties with other phosphoesterase inhibitors would help to clarify this issue.

\section{ACKNOWLEDGMENTS}

We thank Pfizer Inc. (USA) for the generous gifts of sildenafil citrate and atorvastatin calcium, and for permitting the publication of our report. We greatly thank Dr. Micetich for his significant scientific contribution.

\section{REFERENCES}

[1] Rubin, L.J., Introduction: Diagnosis and management of pulmonary arterial hypertension: ACCP evidence-based clinical practice guidelines. Chest. 126: 7S-10S, 2004.

[2] Tuder, R.M., Cool, C.D., Geraci, M.W., Wang, J.,
Abman, S.H., Wright, L., Badesch, D., Voelkel, N.F., Prostacyclin synthase expression is decreased in lungs from patients with severe pulmonary hypertension. Am. J. Respir. Crit. Care. Med. 159: 1925-1932, 1999.

[3] Giaid, A., Saleh, D., Reduced expression of endothelial nitric oxide synthase in the lungs of patients with pulmonary hypertension. N. Engl. J. Med. 333: 214-221, 1995.

[4] Christman, B.W., McPherson, C.D., Newman, J.H., King, G.A., Bernard, G.R., Groves, B.M., Loyd, J.E., An imbalance between the excretion of thromboxane and prostacyclin metabolites in pulmonary hypertension. N. Engl. J. Med, 327: 70-75, 1992.

[5] Giaid, A., Yanagisawa, M., Langleben, D., Michel, R.P., Levy, R., Shennib, H., Kimura, S., Masaki, T., Duguid, W.P., Stewart, D.J., Expression of endothelin-1 in the lungs of patients with pulmonary hypertension. N. Engl. J. Med. 328: 1732-1739, 1993.

[6] Barst, R.J., Rubin, L.J., Long, W.A., McGoon, M.D., Rich, S., Badesch, D.B., Groves, B.M., Tapson, V.F., Bourge, R.C., Brundage, B.H., Koerner, S.K., Langleben, D., Keller, C.A., Murali, S., Uretsky, B.F., Calayton, L.M., Jobsts, M.M., Blackburn, S.D., Shortino, D., Crow, J.W., A comparison of continuous intravenous epoprostenol (prostacyclin) with conventional therapy for primary pulmonary hypertension. The Primary Pulmonary Hypertension Study Group. N. Engl. J. Med. 334: 296-302, 1996.

[7] Rich, S., Kaufmann, E., Levy, P.S., The effect of high doses of calcium-channel blockers on survival in primary pulmonary hypertension. N. Engl. J. Med. 327: 76-81, 1992.

[8] Gomberg-Maitland, M., Olschewski, H., Prostacyclin therapies for the treatment of pulmonary arterial hypertension. Eur. Respir. J. 31: 891-901, 2008.

[9] Rubin, L.J., Badesch, D.B., Barst, R.J., Galie, N., Black, C.M., Keogh, A., Pulido, T., Frost, A., Roux, S., Leconte, I., Landzberg, M., Simonneau, G., Bosentan therapy for pulmonary arterial hypertension. N. Engl. J. Med. 346: 896-903, 2002.

[10] Sastry, B.K., Narasimhan, C., Reddy, N.K., Raju, B.S., Clinical efficacy of sildenafil in primary pulmonary hypertension: a randomized, placebo- 
controlled, double-blind, crossover study. J. Am. Coll. Cardio., 43: 1149-1153, 2004.

[11] Newman, J.H., Lane, K.B., Hypertensive pulmonary vascular disease: dawn of age of prevention? Am. J. Respir. Crit. Care. Med. 162: 2020-2021, 2000.

[12] Rubin, L.J., Therapy of pulmonary hypertension: the evolution from vasodilators to antiproliferative agents. Am. J. Respir. Crit. Care. Med. 166: 1308-1309, 2002.

[13] Kao, P.N., Faul, J.L., Emerging therapies for pulmonary hypertension: striving for efficacy and safety. J. Am. Coll. Cardiol, 41: 2126-2129, 2003.

[14] Shepherd, J., Cobbe, S.M., Ford, I., Isles, C.G., Lorimer, A.R., MacFarlane, P.W., McKillop, J., Packard, C.J., Prevention of coronary heart disease with pravastatin in men with hypercholesterolemia. West of Scotland Coronary Prevention Study Group. N. Engl. J. Med. 333: 1301-1307, 1995.

[15] Maron DJ, Fazio S, Linton MF., Current perspectives on statins. Circulation. 101: 207213, 2000.

[16] Nishimura, T., Faul, J.L., Berry, G.J., Vaszar, L.T., Qiu, D., Pearl, R.G., Kao, P.N., Simvastatin attenuates smooth muscle neointimal proliferation and pulmonary hypertension in rats. Am. J. Respir. Crit. Care Med.. 166: 1403-1408, 2002.

[17] Liao, J.K., Isoprenoids as mediators of the biological effects of statins. J. Clin. Invest. 110: 285-288, 2002.

[18] Kwak, B., Mulhaupt, F., Myit, S., Mach, F., Statins as a newly recognized type of immunomodulator. Nat Med. 6:1399-1402, 2000.

[19] Bustos, C., Hernández-Presa, M.A., Ortego, M., Tuñón, J., Ortega, L., Pérez, F., Díaz, C., Hernández, G., Egido, J., HMG-CoA reductase inhibition by atorvastatin reduces neointimal inflammation in a rabbit model of atherosclerosis. J Am Coll Cardiol. 32:2057-2064, 1998.

[20] Soma, M,R., Donetti, E., Parolini, C., Mazzini, G., Ferrari, C., Fumagalli, R., Paoletti, R., HMG CoA reductase inhibitors: in vivo effects on carotid intimal thickening in normocholesterolemic rabbits. Arterioscler Thromb. 13: 571-578, 1993.

[21] Laufs, U., Marra, D., Node, K., Liao, J.K., 3Hydroxy-3-methylglutaryl-CoA reductase inhibitors attenuate vascular smooth muscle proliferation by preventing rho GTPase-induced down-regulation of p27(Kip1). J Biol Chem. 274: 21926-21931, 1999.

[22] Indolfi, C., Cioppa, A., Stabile, E., Di Lorenzo, E., Esposito, G., Pisani, A., Leccia, A., Cavuto, L., Stingone, A,M., Chieffo, A., Capozzolo, C., Chiariello, M., Effects of hydroxymethylglutaryl coenzyme A reductase inhibitor simvastatin on smooth muscle cell proliferation in vitro and neointimal formation in vivo after vascular injury. J Am Coll Cardiol., 35: 214-221, 2000.

[23] Kureishi, Y., Luo, Z., Shiojima, I., Bialik, A., Fulton, D., Lefer, D.J., Sessa, W.C., Walsh, K., The HMG-CoA reductase inhibitor simvastatin activates the protein kinase Akt and promotes angiogenesis in normocholesterolemic animals. Nat Med., 6:1004-1010, 2000.

[24] Takahashi, T, Kanda, T, Inoue, M, Suzuki, T, Kobayashi, I, Kodama, K, Nagai, R., A selective type $\mathrm{V}$ phosphodiesterase inhibitor, E4021, protects the development of right ventricular overload and medial thickening of pulmonary arteries in a rat model of pulmonary hypertension. Life Sci. 59, 371-377. 1996.

[25] Ghodsi, F., Will J. A., Changes in pulmonary structure and function induced by monocrotaline intoxication. Am J Physiol Heart Circ Physiol. 240: H149-H155, 1981.

[26] Bruner, L.H, Hilliker, K.S, Roth, R.A., Pulmonary hypertension and ECG changes from monocrotaline pyrrole in the rat. Am J Physiol Heart Circ Physiol. 245: H300-H306, 1983.

[27] Inoue, H., Yano, K., Noto, T., Takagi, M., Ikeo, T., Kikkawa, K., Acute and chronic effects of T1032, a novel selective phosphodiesterase type 5 inhibitor, on monocrotaline-induced pulmonary hypertension in rats. Biol Pharm Bull. 25:14221426, 2002.

[28] Laufs, U., Liao, J. K. Post-transcriptional regulation of endothelial nitric oxide synthase mRNA stability by Rho GTPase. J. Biol. Chem. 273: 24266-24271, 1998.

[29] Indolfi, C., Di Lorenzo, E., Perrino, C., Stingone, A.M., Curcio, A., Torella, D., Cittadini, A., Cardone, L., Coppola, C., Cavuto, L., Arcucci, O., Sacca, L., Avvedimento, E.V., Chiariello, M. Hydroxymethylglutaryl coenzyme A reductase inhibitor simvastatin prevents cardiac hypertrophy induced by pressure overload and 
inhibits p21 ras activation. Circulation. 106: 2118 2124, 2002.

[30] Takemoto, M., Node, K., Nakagami, H., Liao, Y., Grimm, M., Takemoto, Y., Kitakaze, M., Liao, J. K. Statins as antioxidant therapy for preventing cardiac myocyte hypertrophy. J. Clin. Invest. 108: 1429-1437, 2001.

[31] Schachter M. Chemical, pharmacokinetic and pharmacodynamic properties of statins: an update. Fundam. Clin. Pharmacol. 19: 117-125, 2005.

[32] Randamised trial of cholesterol lowering in 4444 patients with coronary heart disease: the Scandinavian simvastatin survival study (4S). Lancet. 344: 1383-1389, 1994.

[33] Major outcomes in moderately hypercholesterolemic, hypertensive patients randomized to pravastatin vs usual care: The Antihypertensive and Lipid-Lowering Treatment to Prevent Heart Attack Trial (ALLHAT-LLT). JAMA. 288: 2998-3007, 2002.

[34] Clapp, L. H., Finney, P., Turcato, S., Tran, S., Rubin, L. J., Tinker, A. Differential effects of stable prostacyclin analogs on smooth muscle proliferation and cyclic AMP generation in human pulmonary artery. Am. J. Respir. Cell. Mol. Biol. 26: 194-201, 2002.

[35] Abe, K., Morikawa, K., Hizume, T., Uwatoku, T., Oi, K., Seto, M., Ikegaki, I., Asano, T., Kaibuchi, K., Shimokawa. H. Prostacyclin does not inhibit Rho-kinase: An implication for the treatment of pulmonary hypertension. J. Cardiovasc. Pharmacol. 45: 120-124, 2005.

[36] Sebkhi, A., Strange, J.W., Phillips, S.C., Wharton, J., Wilkins, M.R. Phosphodiesterase type 5 as a target for the treatment of hypoxia-induced pulmonary hypertension. Circulation. 107: 3230-
3235, 2003.

[37] Itoh, T., Nagaya, N., Fujii, T., Iwase, T., Nakanishi, N., Hamada, K., Kangawa, K., Kimura, H. A Combination of oral sildenafil and beraprost ameliorates pulmonary hypertension in rats. Am. J. Respir. Crit. Care. Med. 169: 34-38, 2004.

[38] Clozel, M., Hess, P., Rey, M., Iglarz, M., Binkert, C., Qiu, C., Bosentan, sildenafil, and their combination in the monocrotaline model of pulmonary hypertension in rats. Exp. Biol. Med. (Maywood). 231: 967-973, 2006.

[39] Andersen, C.U., Mulvany, M.J., Simonsen, U., Lack of synergistic effect of molsidomine and sildenafil on development of pulmonary hypertension in chronic hypoxic rats. Eur. J. Pharmacol. 510: 87-96, 2005.

[40] Shafiq, N., Reddy, S., Pandhi, P., Manoj, R., Talwar, K.K., Malhotra, S. Sildenafil for pulmonary hypertension: need for evidence generation. Int J Clin Pharmacol Ther. 46: 644651, 2008.

[41] Clinical efficacy of sildenafil in patients with pulmonary hypertension in functional class II or III. Arch Bronconeumol. 43: 272-276, 2007.

[42] Bendayan, D., Shitrit, D., Kramer, M.R., Combination therapy with prostacyclin and tadalafil for severe pulmonary arterial hypertension: a pilot study. Respirology. 13: 916918, 2008.

[43] Aizawa, K., Hanaoka, T., Kasai, H., Kogashi, K., Kumazaki, S., Koyama, J., Tsutsui, H., Yazaki, Y., Watanabe, N., Kinoshita, O., Ikeda, U.. Longterm vardenafil therapy improves hemodynamics in patients with pulmonary hypertension Hypertens. Res. 29: 123-128, 2006. 